\title{
Dental implant imaging: What do South African dentists and dental specialists prefer?
}

SADJ September 2021, Vol. 76 No. 8 p448 - p456

KR Beshtawi ${ }^{1}$, MT Peck ${ }^{2}$, HM Mahmoud ${ }^{3}$, M Chetty $^{4}$

\section{ABSTRACT}

\section{Aims}

To document the types of imaging modalities that are commonly prescribed during dental implant therapy in South Africa.

\section{Material and methods:}

The radiographic preferences were obtained from practitioners via an electronic survey that was disseminated during local dental conferences, electronic channels (e.g., email lists) of multiple dental schools and local dental scientific societies, and personal interviews. The survey consisted of multiplechoice questions which were designed to investigate the most common radiographic prescriptions during various treatment phases of implant therapy.

\section{Results}

The responses of one hundred and forty-two participants (General practitioners and dental specialists) practising in different South African provinces were collected and assessed. Principally, panoramic radiographs combined with cone beam computed tomography (PAN + CBCT) followed by CBCT, as a single examination (ASE), were the most preferable modalities during the implant planning phase (39\% and 29\%, respectively). During and directly after the surgery, periapical radiographs (ASE) were the most preferred (87\% and 65\%, respectively).

\section{Conclusion}

The most widely preferred radiographic examination during

\section{Author affiliations:}

Author affiliations:
1. Khaled R Beshtawi: B.D.S, MSc, PhD. Dental Faculty, University of the Western Cape, Cape Town, South Africa. ORCID Number: 0000-0003-4864-7826.

2. Mogammad T Peck: BChD, MSc, MChD, MRD, FDS RCSEd, MTD FRCSEd, MBA, PGDip MedEd, PhD, The City of London Dental School, Southgate College, London, United Kingdom. ORCID Number: 0000-0002-4755-057

3. Hussein M Mahmoud: B.D.S, MSc (UWC). Private Practice, Dammam, kingdom Of Saudi Arabia.

4. Manogari Chetty: BSc, BChD, MChD, PhD. Department of Craniofacial Biology, Dental Faculty, University of the Western Cape, Cape Town, South Africa. ORCID 0000-0002-1176-8539

Corresponding author: Manogari Chetty

Private Bag X1, Tygerberg, Cape Town, 7505, South Africa.

Email: mchetty@uwc.ac.za

\footnotetext{
The role played and the respective contribution: Conceptualization: KR Beshtawi, M Chetty, MT Peck Analysis: KR Beshtawi, HM Mahmoud Writing - Original Draft: KR Beshtawi Writing - Review \& Editing: KR Beshtawi, M Chetty Supervision: M Chetty, MT Peck
}

the planning of implants was panoramic radiographs combined with CBCT. Periapical radiographs (ASE) were favoured during, directly after the treatment, and during the follow-up of asymptomatic patients by the majority of participants. However, CBCT (ASE) was preferred in the follow up of symptomatic patients. Factors related to extra anatomical information and superior dimensional accuracy provided by three-dimensional volumes (e.g., CBCT volumes), were the most indicated influencing factors on the radiographic prescriptions during implant planning.

\section{Keywords}

Dental implant, radiographic prescription, survey, CBCT.

\section{INTRODUCTION}

Dental radiology is an integral part of dental implant therapy, providing information on the anatomy, boundaries, possible jaw pathologies, and remaining bone quantity and quality of the potential implant site..$^{1,2}$

Various imaging modalities can be utilized during implant therapy with panoramic radiographs being widely used. ${ }^{2}$ During implant treatment, the use of panoramic radiographs was reported ${ }^{3-5}$, and even as a single examination. ${ }^{6}$ The panoramic radiographs do provide multiple advantages which include lower costs, reduced radiation exposure (compared with three-dimensional modalities), ease of use, and availability. ${ }^{3-5}$

Cone-beam computed tomography (CBCT) is a relatively recent and promising technology that has become increasingly popular during various dental treatments including implant placements. ${ }^{7}$ This modality provided a threedimensional perspective on the surgical site while exposing the patients to dosages that are much less than Computed Tomography $(\mathrm{CT})$. $^{\text {? }}$

Multiple organizations and scientific committees have released guidelines/advisory recommendations which are specific for a geographical region (e.g. the American Academy of Oral and Maxillofacial Radiology (AAOMR), the European Association for Osseointegration (E.A.O.), the European Commission, the International Congress of Oral Implantologists (ICOI))., ${ }^{2,8-11}$ There is a paucity of compelling evidence to support the efficacy of using cross-sectional radiographic techniques over conventional counterparts (i.e. 2D imaging) during implant planning. 2,7,12 Treatment methodologies and information acquired from educators 
at various educational levels, competent knowledge of handling recent imaging modalities, and economic strains influence a clinician's radiographic prescription. ${ }^{13}$

In South Africa (SA), CBCT was reported to become a common procedure and even a routine procedure in some practices for screening purposes. ${ }^{14}$ This is especially true particularly with the absence of rigorous local radiographic guidelines which could inform specific criteria for the management of patients requiring implant therapy. In this article, the authors report on the radiographic prescriptions, preferences and clinical opinions of a sample of dental practitioners who perform implant therapy in various South African provinces.

\section{MATERIAL AND METHODS}

An electronic questionnaire was developed and published online using Google ${ }^{\circledR}$ Forms ${ }^{\circledR}$ after obtaining ethical approval for degree purposes (Number: BM19/1/20, University of the Western Cape, South Africa). The survey was constructed with 17 open-ended multiple-choice questions. All the information with respect to the research and the questionnaire (information sheet) was attached to the survey. A consent form was presented at the beginning of the online survey. No names nor personal information was required and anonymity of the participants was maintained.

The questions were formulated to allow for anonymous and scenario-based investigations on the radiographic analysis executed/preferred during implant therapy in South Africa (in various phases of the treatment). The questions probed data on the most used imaging modalities, personal experiences, clinical preferences, and the possible factors that may influence radiographic prescriptions. Only two questions were allowed to record multiple selections (answers). The level of formal training received (e.g., general dentist, postgraduate student, specialist) and the province where participants practised, were captured.

The imaging modality preferences were assessed during different clinical situations, various anatomical regions, and embraced all the phases of dental implant therapy (planning, intra-operative, and follow-up phases). The anatomical regions that were assessed during the planning phase include the posterior mandible (unilateral, distal to first premolar region), anterior region of the maxilla/mandible (canine to canine region), posterior maxillary region (unilateral: distal to the first premolar), one jaw (mandible/ maxilla) or both jaws (full mouth), and the mental foramen region (uni/bilateral). The imaging modalities options were: periapical radiograph/s (PA) only, panoramic radiograph (PAN) only, PAN + PA, PA + CBCT, PAN + CBCT,

\begin{tabular}{|c|c|}
\hline Survey dissemination channel /platform & $\begin{array}{l}\text { Number of } \\
\text { surveyees }\end{array}$ \\
\hline - Conferences and academic meetings & 40 \\
\hline - Online channels (e.g., mailing lists) & 71 \\
\hline - Academic institutions (interviews and online) & 31 \\
\hline - Total number of participants & 142 \\
\hline
\end{tabular}

CBCT only, and no radiographs. Motivating factors for the selection of radiographic examinations, such as cost, availability, radiation dose concerns, broad coverage (i.e., the extent of the anatomical area depicted in a single radiographic examination), dimensional accuracy (3D volumes), additional anatomical information (3D volumes), and special procedures (e.g., 3D volumes for guided implant surgery) were also explored.

\section{Inclusion criteria:}

1. Clinicians, academics, specialists, and senior residents in the Departments of Periodontology, Prosthodontics, Oral maxillofacial surgery, and Oral and Maxillofacial Radiology, who are engaged in dental implant therapy in the South African dental schools.

2. Dental specialists who perform implant treatments in private practice.

3. Dental practitioners in private practice with experience performing dental implantology not less than three years.

The survey was disseminated online via email list of the South African dental association (SADA) and scientific societies (SA society for Periodontics, Implantology \& Oral Medicine, and SA society of Maxillofacial \& Oral Surgeons). Also, the online survey was provided by email or personal interviews (where was applicable) to academics in various related departments at SA dental faculties, and practitioners who participated in several conferences held in SA (including the ITI implant Congress (Cape Town, SA, July 2019) and the SADA congress (held in Durban, SA, September 2019). A hard-copy format of the survey was offered upon request from the participant. The interviewers (where applicable) were trained and calibrated to the format and questions of the questionnaire, and, if necessary, answers to any inquiries, were provided without impacting the participant's choices. Descriptive statistics were used to describe the collected survey data.

\section{RESULTS}

142 dental clinicians participated in the survey (Table I) with the majority of them practising in the Western Cape province (Chart 1; this excluded 47 surveyees where their practice location was failed to be captured).

Sixty-three participants (44\%) were general dentists with implant experience (3 years min.), followed by 28 periodontists (20\%), 16 registrars (11\%), 15 maxillofacial surgeons (11\%), 12 prosthodontists (8\%), and 8 maxillofacial radiologists (6\%), (Chart 2).

Panoramic radiograph accompanied by CBCT examination were the most selected imaging modalities (39\%) during the implant planning phase (in all anatomical regions in the jaws). This was followed by CBCT as a single examination (29\%), periapical radiograph (PA) with CBCT (19\%), PAN + PA (8\%), PAN only (2\%), other $(2 \%)$, and PA only (1\%). Table II and Chart 3 (A-E) shows in detail the imaging modalities preferred for each questioned anatomical site. In general, "Three-dimensional modalities provide more anatomical information necessary for the success of the therapy" followed by "Better dimensional 


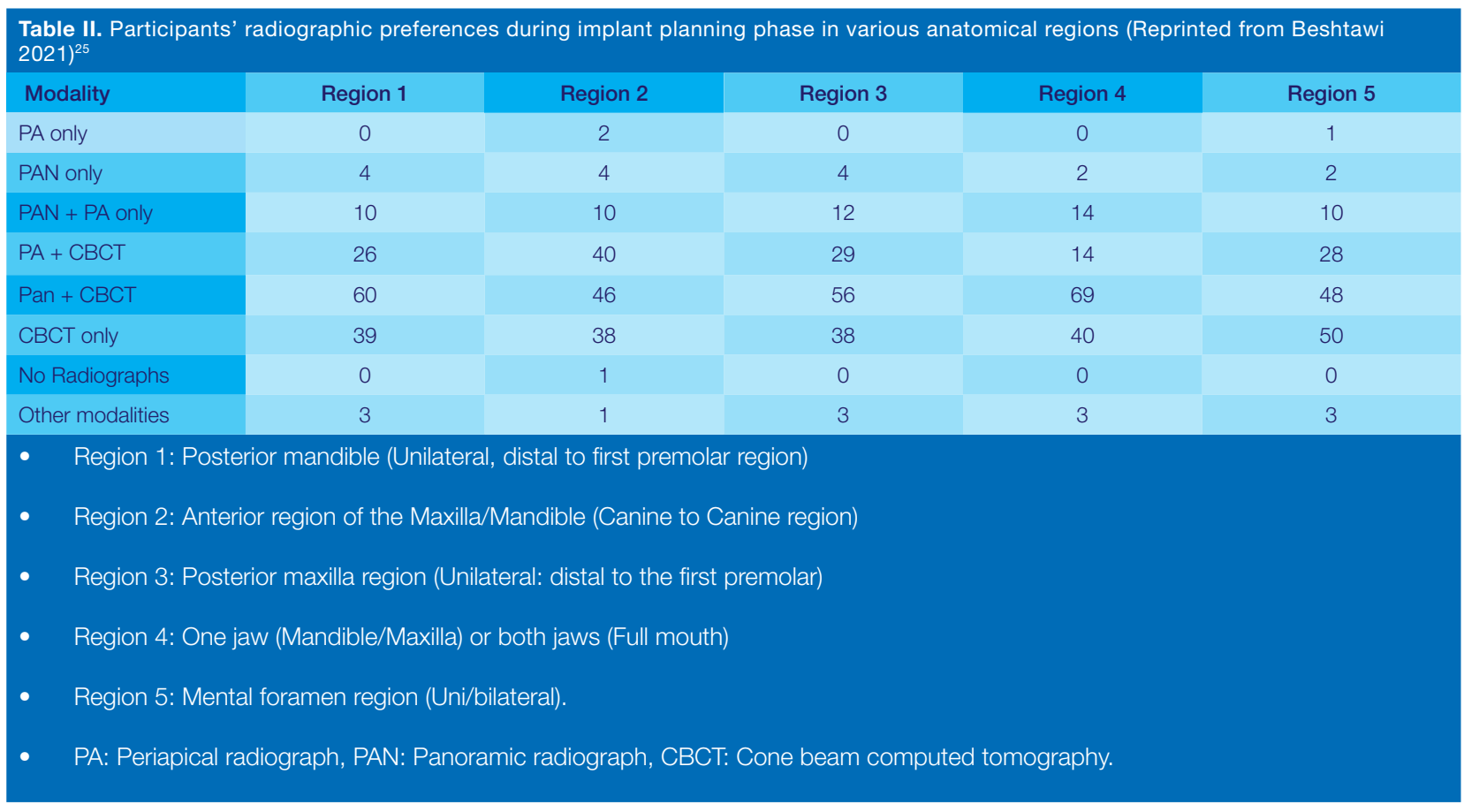

accuracy (if three-dimensional modalities, e.g., CBCT, were selected previously)", and followed by broad coverage of the anatomical region were the most chosen factors to influence the prescriptions of radiographic techniques during the implant planning phase (Table III and Chart 4).

During and directly after surgery (Table IV and Chart 5 A\&B), periapical radiography (ASE) was the most selected modality (87\% and 65\%, respectively). During follow-up (Table V and Chart 6) of asymptomatic patients, PA (ASE) was also the most selected by $46 \%$; Nonetheless, in the presence of postoperative complications, CBCT (ASE) was mostly preferred (32\%). The CBCT was preferred the most during follow-up of symptomatic patients due to the extra information it provides regardless of any radiographic artefacts that could occur (caused by implants). Besides, the participants also claimed that broad coverage, availability and ease of access are factors that influence the imaging modality of choice during the follow-up phase (Table VI).

The majority of surveyees (56\%) indicated that radiographic follow-up frequency (i.e., after the delivery of the prosthesis) was "After the first 6 months, 12 months, and then every year for a 10-year period" (Chart 7).

Comparisons between the level of formal training and the most frequently selected radiographic examination during various treatment phases, along with the motivating factors for their choice, were noted (Tables VII-IX).

\section{DISCUSSION}

It is evident from the results of this survey, that panoramic radiographs and CBCT were the most preferred combination for implant planning purposes among South African dentists. The CBCT modality was predominantly selected as a single examination or in combination with other modalities during the planning phase with an average of $91 \%$ of selections. Nevertheless, a variation of the preferred modalities depending on the anatomical region of the implant site was noted. Minor variations in the preferred radiographic examination were found between various dental speciali-
Table III. Participants' indicated factors that impact the radiographic modality choice in planning phase (Reprinted from Beshtawi 2021)

Factors (Multiple answers were allowed):

Participants $(n=142)$

Lower costs for the patients (if the conventional modalities PAN and/or PA were preferred previously)

Availability and ease of access of the radiographic modality (if the conventional modalities PAN and/or PA were preferred previously)

Radiation dose concerns of three-dimensional modalities (if the conventional modalities PAN and/or PA were preferred previously)

Broad coverage of the designated anatomical area (If PAN and/or CBCT were preferred previously)

Better dimensional accuracy (if three-dimensional modalities, e.g., CBCT, were selected previously)

Three-dimensional modalities provide more anatomical information necessary for the success of the therapy

Only three-dimensional modalities (e.g., CBCT), if guided implant surgery is considered

Other reasons

Table VI. Participants' indicated factors that impact the radiographic modality choice during follow-up phase (Reprinted from Beshtawi 2021) 25

Factors (Multiple answers were allowed):

Conventional radiographs (especially PA) are preferred, as the CBCT is of limited value if radiographic artefacts (caused by implants e.g., beam hardening and scattering) are evident in the volume.

CBCT provides more information regardless of the limitations of possible beam radiographic artefacts caused by the implants

Availability and ease of access of the radiographic modality

Broad coverage of the designated anatomical area

Other reasons

Three-dimensional modalities provide more anatomical information necessary for the success of the therapy

Only three-dimensional modalities (e.g., CBCT), if guided implant surgery is considered

Other reasons 


\begin{tabular}{|c|c|c|}
\hline Modality & $\begin{array}{l}\text { During the implant } \\
\text { surgery }\end{array}$ & $\begin{array}{l}\text { Directly after the } \\
\text { implant surgery }\end{array}$ \\
\hline Periapical radiograph & 123 & 92 \\
\hline Panoramic radiograph & 2 & 26 \\
\hline CBCT only & 7 & 18 \\
\hline No radiographs & 10 & 6 \\
\hline
\end{tabular}

Table V. Participants' radiographic preferences during the followup of symptomatic and asymptomatic patients (Reprinted from Beshtawi 2021) ${ }^{25}$

\begin{tabular}{c|c|c|}
\hline Modality & Asymptomatic & Symptomatic \\
\hline $\begin{array}{c}\text { Periapical radiograph/s } \\
\text { (PA) only }\end{array}$ & 66 & 11 \\
$\begin{array}{c}\text { Panoramic radiograph } \\
\text { (PAN) only }\end{array}$ & 20 & 5 \\
PAN + PA only & 25 & 21 \\
PA + CBCT & 1 & 37 \\
Pan + CBCT & 8 & 17 \\
CBCT only & 12 & 46 \\
No Radiographs & 6 & 0 \\
Others & 4 & 5 \\
\hline
\end{tabular}

ties, therapy phases, and the anatomical regions of interest. CBCT (ASE) was predominantly favoured by OMFS and periodontists during implant planning in all anatomical regions investigated. On the contrary, prosthodontists and registrars predominantly preferred panoramic radiographs combined with CBCT. Both CBCT (ASE) and with combination with panoramic radiographs were selected by the majority of OMFR; while general practitioners pre- ferred CBCT either with panoramic radiographs or PA (only in one anatomic region investigated). During and immediately after the surgical phase, the majority of all participants preferred periapical radiographs (ASE).

During the follow-up of asymptomatic patients, PA only was preferred by periodontists, GP, registrars, and OMFR, while most prosthodontists and OMFS preferred PAN (ASE). However, during the follow-up of symptomatic patients, the prosthodontists, OMFS, OMFR, and registrars concurred on CBCT (ASE), while most GPs favoured a combination of PA and CBCT examinations. Moreover, PA and CBCT volumes and CBCT (ASE) were preferred by periodontists $(39 \%, 39 \%$, respectively) during the follow-up of symptomatic patients.

Fifty-six percent of participants indicated a followup frequency to be after 6,12 months and annually afterwards for ten years.

Three-dimensional volumes were claimed to allow proper examination during the planning phase by providing extra anatomical details that are vital for the treatment success and, at the same time, advocating better dimensional accuracy. Moreover, broad coverage provided by a given imaging modality was a nonnegligible factor; while cost-related factors and radiation dose concerns were the least to affect their radiographic choices. On the other hand, $47 \%$ of participants advocated the useful use of CBCT regardless of any possible radiographic artefacts (e.g., beam hardening, caused by the implant body) during the assessment of symptomatic patients.

\begin{tabular}{|c|c|c|c|c|c|c|c|c|}
\hline \multicolumn{3}{|c|}{ Region } & GP (63) & $\begin{array}{l}\text { Periodontists } \\
\text { (28) }\end{array}$ & $\begin{array}{l}\text { Prosthodon- } \\
\text { tists (12) }\end{array}$ & OMFS (15) & OMFR (8) & Registrars (16) \\
\hline & \multirow{2}{*}{ Region 1} & Overall & $\begin{array}{c}\mathrm{PAN}+\mathrm{CBCT} \\
(43 \%)\end{array}$ & СВCТ (43\%) & $\begin{array}{c}\text { PAN +CBCT } \\
(59 \%)\end{array}$ & СВCТ (46\%) & $\begin{array}{c}\mathrm{PAN}+\mathrm{CBCT} \\
(62 \%)\end{array}$ & $\begin{array}{c}\mathrm{PAN}+\mathrm{CBCT} \\
(56 \%)\end{array}$ \\
\hline & & $\% \mathrm{CBCT}^{\star}$ & 51 (80.95\%) & 27 (96.42\%) & 10 (83.33\%) & 14 (93.33\%) & $8(100 \%)$ & 15 (93.75\%) \\
\hline & \multirow{2}{*}{ Region 2} & Overall & $\begin{array}{c}\mathrm{PA}+\mathrm{CBCT} \\
(35 \%)\end{array}$ & CBCT (50\%) & $\begin{array}{c}\text { PAN +CBCT } \\
(67 \%)\end{array}$ & СBCT (53\%) & СВCТ (38\%) & $\begin{array}{c}\mathrm{PAN}+\mathrm{CBCT} \\
(50 \%)\end{array}$ \\
\hline & & $\% \mathrm{CBCT}^{*}$ & 50 (79.36\%) & 26 (92.85\%) & 10 (83.33\%) & 14 (93.33\%) & $8(100 \%)$ & 16 (100\%) \\
\hline & \multirow[t]{2}{*}{ Region 3} & Overall & $\begin{array}{c}\text { PAN+CBCT } \\
(35 \%)\end{array}$ & СВCT (39\%) & $\begin{array}{c}\text { PAN +CBCT } \\
(67 \%)\end{array}$ & СBCT (60\%) & $\begin{array}{c}\text { PAN +CBCT } \\
(50 \%)\end{array}$ & $\begin{array}{c}\mathrm{PAN}+\mathrm{CBCT} \\
(63 \%)\end{array}$ \\
\hline & & $\% \mathrm{CBCT}^{\star}$ & 49 (77.77\%) & 27 (96.42\%) & 10 (83.33\%) & 14 (93.33\%) & $8(100 \%)$ & 15 (93.75\%) \\
\hline \multirow[t]{4}{*}{$\begin{array}{l}\text { Planning } \\
\text { phase }\end{array}$} & \multirow{2}{*}{ Region 4} & Overall & $\begin{array}{c}\text { PAN+CBCT } \\
(52 \%)\end{array}$ & CBCT (53\%) & $\begin{array}{c}\text { PAN +CBCT } \\
(67 \%)\end{array}$ & CBCT (53\%) & $\begin{array}{c}\text { PAN +CBCT } \\
(62 \%)\end{array}$ & $\begin{array}{c}\text { PAN +CBCT } \\
(62 \%)\end{array}$ \\
\hline & & $\% \mathrm{CBCT}^{*}$ & 51 (80.95\%) & $26(92,85 \%)$ & $9(75 \%)$ & 14 (93.33\%) & $8(100 \%)$ & 15 (93.75\%) \\
\hline & \multirow[t]{2}{*}{ Region 5} & Overall & $\begin{array}{c}\text { PAN+CBCT } \\
(36 \%)\end{array}$ & СВCT (57\%) & $\begin{array}{c}\text { PAN +CBCT } \\
(50 \%)\end{array}$ & СВCТ (67\%) & $\begin{array}{c}\mathrm{PAN}+\mathrm{CBCT} \\
\& \text { CBCT only } \\
(50 \%)\end{array}$ & $\begin{array}{c}\text { PAN +CBCT } \\
(50 \%)\end{array}$ \\
\hline & & & 52 (82.53\%) & $26(92,85 \%)$ & 11 (91.66\%) & 14 (93.33\%) & $8(100 \%)$ & $15(93.75 \%)$ \\
\hline \multirow{2}{*}{\multicolumn{9}{|c|}{$\begin{array}{l}\text { - } \text { Percentage of selections included CBCT (as a single examination or combir } \\
\text { - } \quad \text { Region 1: Posterior mandible (Unilateral, distal to first premolar region) } \\
\text { - } \quad \text { Region 2: Anterior region of the Maxilla/Mandible (Canine to Canine region) }\end{array}$}} \\
\hline & & & & & & & & \\
\hline \multicolumn{9}{|l|}{ 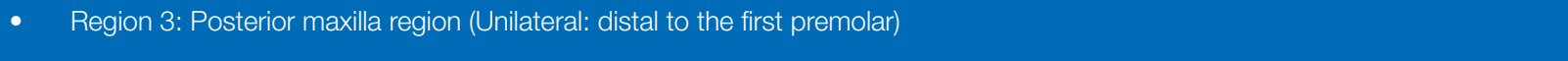 } \\
\hline \multicolumn{9}{|c|}{$=$} \\
\hline \multicolumn{9}{|c|}{. } \\
\hline GF & eneral k & ange $\Omega$ & MED. $\cap r$ & & & & & \\
\hline
\end{tabular}




\begin{tabular}{|c|c|c|c|c|c|c|c|}
\hline \multicolumn{2}{|c|}{ Phase } & GP (63) & $\begin{array}{l}\text { Periodontists } \\
\text { (28) }\end{array}$ & $\begin{array}{l}\text { Prosthodontists } \\
\text { (12) }\end{array}$ & OMFS (15) & OMFR (8) & Registrars (16) \\
\hline \multirow{2}{*}{$\begin{array}{l}\text { During the } \\
\text { surgery }\end{array}$} & Overall & PA (90\%) & PA (96\%) & PA (83\%) & PA (67\%) & PA (75\%) & PA (81\%) \\
\hline & $\% \mathrm{CBCT}^{*}$ & $3(4.76 \%)$ & 1 (3.57\%) & 0 & $1(6.66 \%)$ & $1(12.5 \%)$ & 1 (6.25\%) \\
\hline \multirow{2}{*}{$\begin{array}{l}\text { Directly after the } \\
\text { surgery }\end{array}$} & Overall & PA (70\%) & PA (64\%) & PA (50\%) & PA (40\%) & PA (62\%) & PA (81\%) \\
\hline & $\% \mathrm{CBCT}^{*}$ & $8(12.69 \%)$ & 6 (21.42\%) & 0 & 2 (13.33\%) & $2(25 \%)$ & 0 \\
\hline \multirow{2}{*}{$\begin{array}{l}\text { Follow-up } \\
\text { (Asymptomatic } \\
\text { patient) }\end{array}$} & Overall & PA (59\%) & PA (50\%) & PAN (25\%) & PAN (53\%) & PA (62\%) & PA (44\%) \\
\hline & $\% \mathrm{CBCT}^{*}$ & 8 (12.69\%) & $3(10.71 \%)$ & 2 (16.66\%) & 2 (13.33\%) & 1 (12.5\%) & 5 (31.25\%) \\
\hline \multirow{2}{*}{$\begin{array}{l}\text { Follow-up } \\
\text { (symptomatic } \\
\text { patient) }\end{array}$} & Overall & $\begin{array}{c}\mathrm{PA}+\mathrm{CBCT} \\
(32 \%)\end{array}$ & $\begin{array}{l}\mathrm{PA}+\mathrm{CBCT} \text { and } \\
\text { CBCT only (39\%) }\end{array}$ & СВCT (41\%) & СВCT (40\%) & СВCТ (43\%) & СВСТ (50\%) \\
\hline & $\% \mathrm{CBCT}^{\star}$ & 38 (60.31\%) & 23 (82.14\%) & 9 (75\%) & 10 (66.66\%) & $6(75 \%)$ & 14 (87.5\%) \\
\hline
\end{tabular}

* Percentage of selections included CBCT (as a single examination or combined with other techniques)

Table IX. Number of GPs and specialists versus the indicated motivating factor of to select a certain radiographic modality during planning phase (Reprinted from Beshtawi 2021) ${ }^{25}$

\begin{tabular}{|c|c|c|c|c|c|c|}
\hline Motivating factor & GP (\% of 63$)$ & $\begin{array}{l}\text { Periodontists }(\% \\
\text { of } 28)\end{array}$ & $\begin{array}{l}\text { Prosthodontists } \\
\text { (\% of } 12)\end{array}$ & $\begin{array}{l}\text { OMFS } \\
\text { (\% of } 15)\end{array}$ & $\begin{array}{l}\text { OMFR } \\
(\% \text { of } 8)\end{array}$ & $\begin{array}{l}\text { Registrars } \\
\text { (\% of } 16)\end{array}$ \\
\hline $\begin{array}{l}\text { Lower costs for the patients (if the con- } \\
\text { ventional modalities PAN and/or PA were } \\
\text { preferred previously) }\end{array}$ & 10 (15.9\%) & $0(0 \%)$ & 1 (8.3\%) & $0(0 \%)$ & $0(0 \%)$ & $0(0 \%)$ \\
\hline $\begin{array}{l}\text { Availability and ease of access of the } \\
\text { radiographic modality (if the conventional } \\
\text { modalities PAN and/or PA were preferred } \\
\text { previously) }\end{array}$ & 15 (23.8\%) & $0(0 \%)$ & $0(0 \%)$ & $2(13,3 \%)$ & $0(0 \%)$ & 2 (12.5\%) \\
\hline $\begin{array}{l}\text { Radiation dose concerns of three- } \\
\text { dimensional modalities (if the conventional } \\
\text { modalities PAN and/or PA were preferred } \\
\text { previously) }\end{array}$ & 2 (3.2\%) & 2 (7.1\%) & $0(0 \%)$ & 1 (6.7\%) & $1(12.5 \%)$ & 1 (6.25\%) \\
\hline $\begin{array}{l}\text { Broad coverage of the designated ana- } \\
\text { tomical area (If PAN and/or CBCT were } \\
\text { preferred previously) }\end{array}$ & 29 (46\%) & 12 (42.9\%) & 7 (58.3\%) & 7 (46.7\%) & $6(75 \%)$ & $8(50 \%)$ \\
\hline $\begin{array}{l}\text { Better dimensional accuracy (if three- } \\
\text { dimensional modalities, e.g., CBCT, were } \\
\text { selected previously) }\end{array}$ & 37 (58.7\%) & 13 (46.4\%) & 10 (83.3\%) & 11 (73.3\%) & 7 (87.5\%) & $8(50 \%)$ \\
\hline $\begin{array}{l}\text { Three-dimensional modalities provide } \\
\text { more anatomical information necessary for } \\
\text { the success of the therapy }\end{array}$ & 41 (65.1\%) & 24 (85.7\%) & 10 (83.3\%) & $13(86.7 \%)$ & $6(75 \%)$ & $14(87.5 \%)$ \\
\hline $\begin{array}{l}\text { Only three-dimensional modalities (e.g., } \\
\text { CBCT) if guided implant surgery is } \\
\text { considered }\end{array}$ & $11(17.5 \%)$ & 4 (14.3\%) & 1 (8.3\%) & 5 (33.3\%) & 5 (62.5\%) & 2 (12.5\%) \\
\hline Other reasons & $3(4.8 \%)$ & $0(0 \%)$ & $1(8,3 \%)$ & $1(6,7 \%)$ & $0(0 \%)$ & $0(0 \%)$ \\
\hline
\end{tabular}

Chart 1. Participants' provinces of practice.

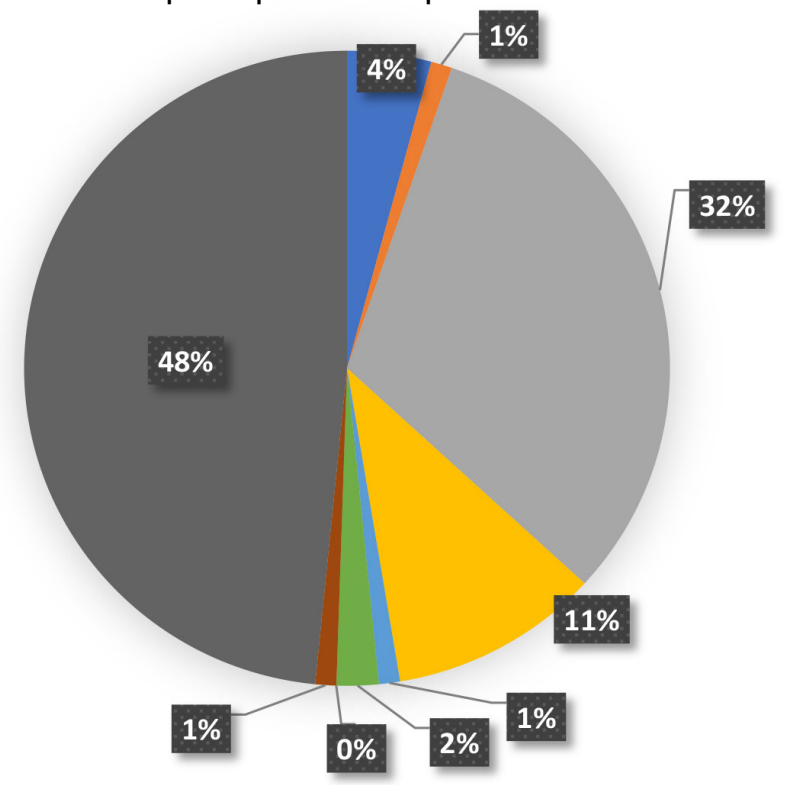
Eastern Cape
Free State
Gauteng
KwaZulu-Natal
Limpopo
Mpumalanga
Northern Cape
North West
Western Cape 
Chart 2. Distribution of the formal training of the sur

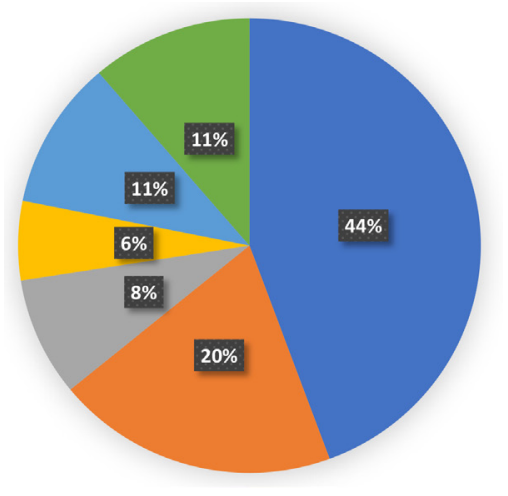

General dentist with implant experience (3Years Min.)

Periodontist

Prosthodontists

Oral and Maxillofacial radiology

Oral and Maxillofacial surgeon

Registrar (Perio., Prosth., OMFS)

Chart 3. Distribution of the preferred radiographic modalities during planning phase (A-E).

Chart 3A: Posterior mandible

(Unilateral, distal to first premolar region )

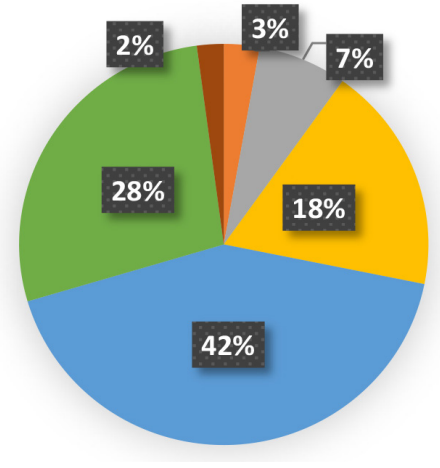

Chart 3C: Posterior maxilla region

(Unilateral: distal to the first premolar)

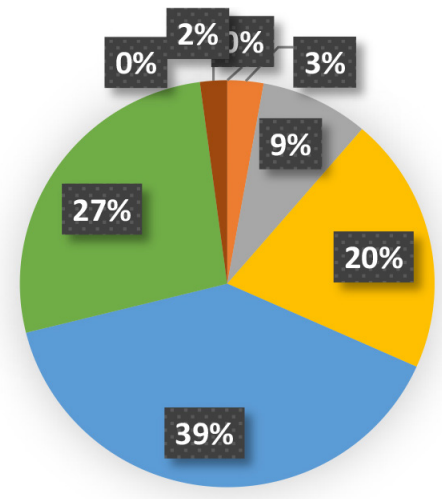

Chart 3E: Mental foramen region (Uni/bilateral)

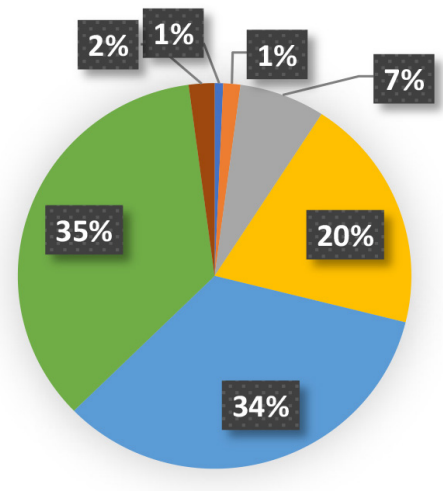

Chart 3B: Anterior region of the maxilla/mandible (Canine to Canine region)

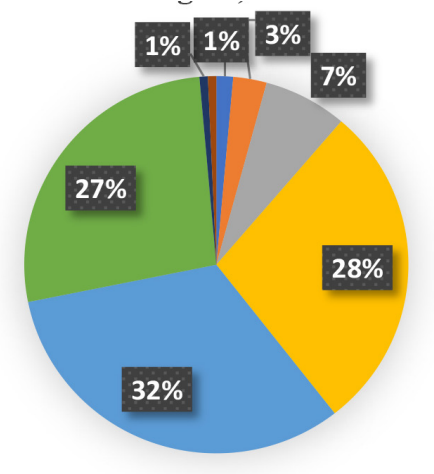

Chart 3D: One jaw (Mandible/Maxilla) or both jaws (Full mouth)

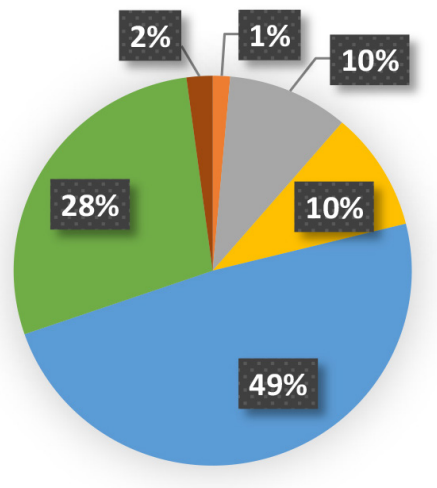

Periapical radiograph/s (P.A) only

Panoramic radiograph (PAN) only

PAN + P.A only

$P . A+C B C T$

$\mathrm{PAN}+\mathrm{CBCT}$

CBCT only

No Radiographs

Others 
Chart 4. Indicated factors impacting the radiographic preference during implant planning phase.

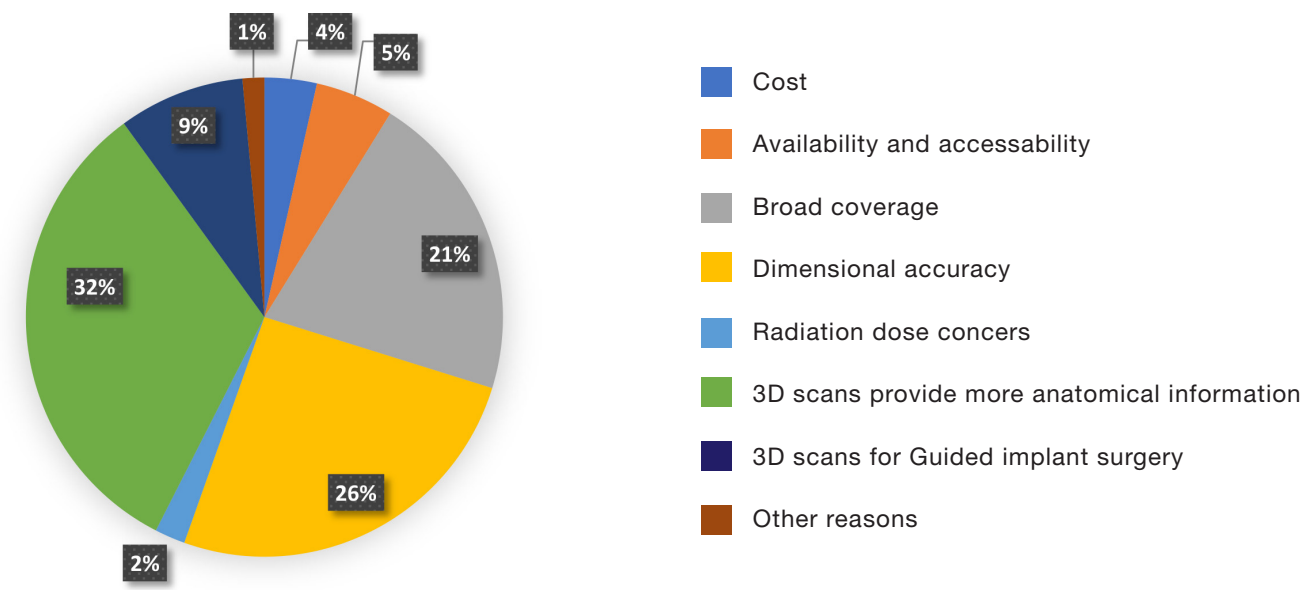

Chart 5. Radiographic modalities preference during and directly after surgery (A\&B).

Chart 5A: During the surgery

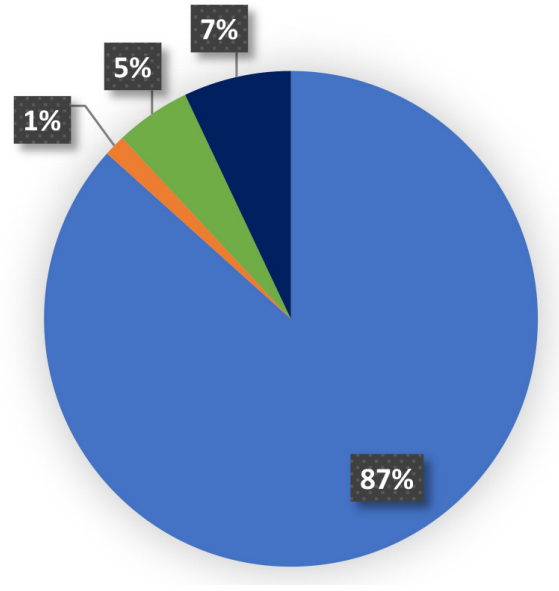

Chart 5B: Directly after the surgery

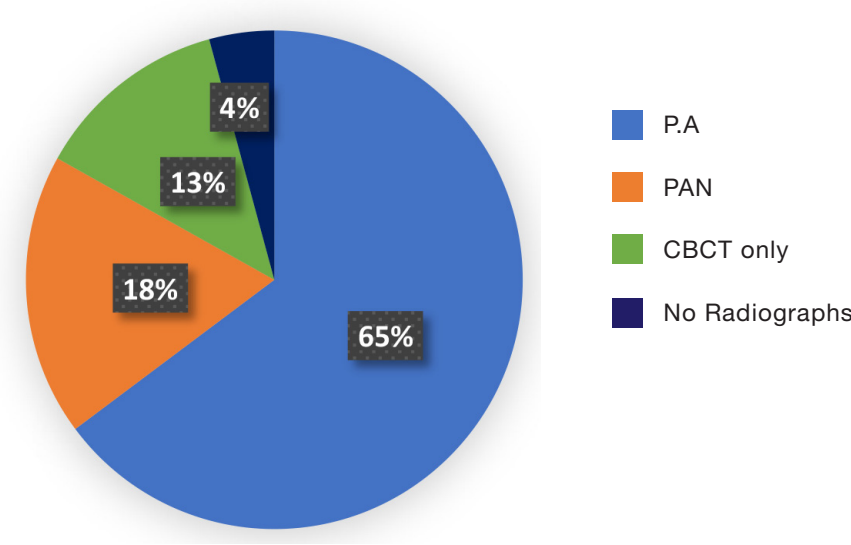

Chart 6. Radiographic modalities preference during the follow-up of asymptomatic and symptomatic patients (A\&B).

Chart 6A: Follow-up

(Asymptomatic patient)

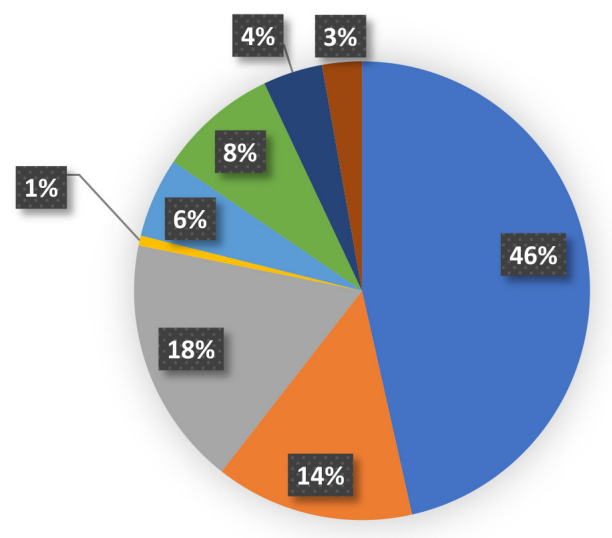

Periapical radiograph/s (P.A) only

Panoramic radiograph (PAN) only

PAN $=$ P.A only

Chart 6B: Follow-up

$\mathrm{P} . \mathrm{A}+\mathrm{CBCT}$

(Symptomatic patient)

$\mathrm{PAN}+\mathrm{CBCT}$

CBCT only

No Radiograhs

Others

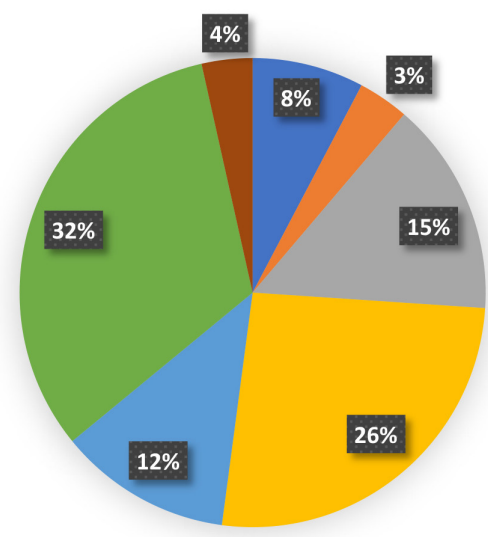


Chart 7. Frequency of radiographic follow-up (after the delivery of the prosthesis).

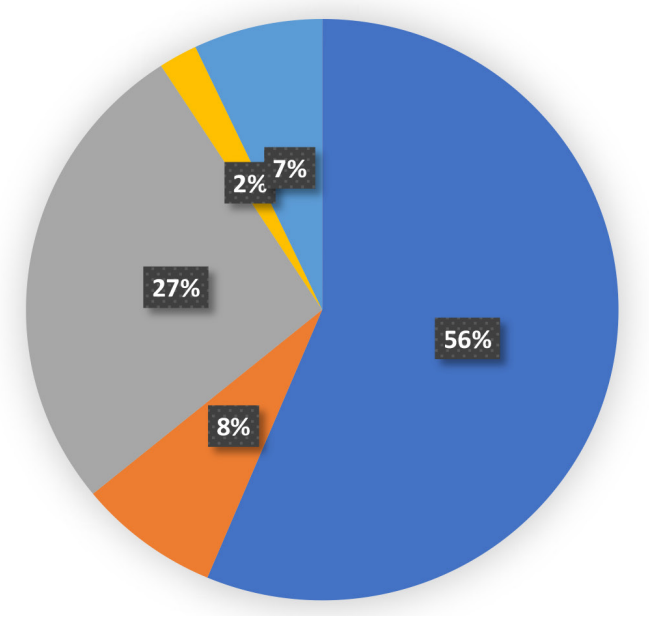

After the first 6 months, 12 months and then every year for a 10 year period.

Every year for a 10 year period.

After the first 6 months, 12 months and then every year for a 3 year period.

Every three years for ten years.

Other

Panoramic radiographs (ASE) were shown to be the most popular technique during the planning phase in India15-18 due to mainly the availability and broad coverage factors. Panoramic radiographs (ASE) were also found the most popular during the planning phase in surveys conducted in Brazil $^{19}$, Palestine ${ }^{20}$, and Libya ${ }^{21}$. In Saudi Arabia ${ }^{22}, 20.2 \%$ (the highest percentage) preferred PAN, PA, and CT during the pre-operative phase. In turkey ${ }^{23}$, CBCT prescriptions were mostly indicated for implant planning. In Italy ${ }^{24}$, 84\% of participants in a survey indicated the use of intraoral periapical radiographs, $8.8 \%$ preferred panoramic radiographs, and $6.9 \%$ preferred $\mathrm{CBCT}$ during the followup phase.

Inconsistency related to radiographical prescriptions for implant planning at the international level was mentioned ${ }^{13}$ for being independent of social wealth and the level of "dental health".

In the light of international guidelines

The AAOMR2 advised in 2012 that "cross-sectional imaging be used for the assessment of all dental implant sites and that CBCT is the imaging method of choice for gaining this information". On the other hand, the E.A.O guidelines ${ }^{8}$ published in 2012 stated that in case of the presence of adequate bone width after clinical evaluation, along with sufficient bone height and clear demarcation of the anatomical boundaries observed on conventional radiographs, then there is no need for further imaging.

Nevertheless, E.A.Omentioned theadvantages of cross-sectional imaging e.g., better anatomical structure demarcation, promoting the prosthetic outcomes, assessment of bone defects, in case of bone augmentation, special techniques (e.g., zygomatic implants), and during computer-guided implantology. The $\mathrm{ICOI}^{11}$ advised the use of CBCT must be justified on an individual basis and after a full clinical assessment. Nevertheless, "..., it is virtually impossible to predict which treatment cases would not benefit from having this additional information before obtaining it"11.

The findings of this investigation aimed at enriching the pool of evidence in South Africa with regards to the local imaging practices. Such type of evidence would help the decision-makers at local radiation regulatory authorities to formulate imaging guidelines that adapt/harmonize with the needs of the clinicians and the local working environment.

\section{CONCLUSION}

The majority of the surveyed south African dentists preferred the combination of panoramic radiographs and CBCT volumes for the implant planning phase, while the vast majority concur on the use of periapical radiographs (ASE) during and immediately after surgery. Periapical radiographs were also mostly chosen during the follow-up of asymptomatic patients and, by contrast, СBCT for those who appear with symptoms. The surveyed clinicians believe that CBCT provides extra anatomical information that is dimensionally more accurate.

\section{Acknowledgements}

The authors would like to thank the following for their valuable assistance:

- Research Senate, University of the Western Cape, South Africa for funding this project.

- South African Dental Association, the South African Society of Maxillo-Facial and Oral Surgeons, the South African Society for Periodontology, and Straumann ${ }^{\circledR}$ Group SA.

\section{Disclosure}

The authors declare no conflict of interest. This article is submitted out of a successful PhD study, that was funded by Senate Research, University of the Western Cape, South Africa.

\section{References}

1. Tyndall DA, Brooks SL. Selection criteria for dental implant site imaging: a position paper of the American Academy of Oral and Maxillofacial radiology. Oral Surg Oral Med Oral Pathol Oral Radiol Endod. 2000 May;89(5):630-7.

2. Tyndall DA, Price JB, Tetradis S, Ganz SD, Hildebolt C, Scarfe WC, et al. Position statement of the American Academy of Oral and Maxillofacial Radiology on selection criteria for the use of radiology in dental implantology with emphasis on cone beam computed tomography. Oral Surg Oral Med Oral Pathol Oral Radiol. 2012 Jun;113(6):817-26.

3. Vazquez L, Saulacic N, Belser U, Bernard JP. Efficacy of panoramic radiographs in the preoperative planning of posterior 
mandibular implants: A prospective clinical study of 1527 consecutively treated patients. Clin Oral Implants Res. 2008;19(1):81-5.

4. Kim YK, Park JY, Kim SG, Kim JS, Kim JD. Magnification rate of digital panoramic radiographs and its effectiveness for pre-operative assessment of dental implants. Dentomaxillofacial Radiol. 2011;40(2):76-83.

5. Assaf M, Gharbyah A. Accuracy of Computerized Vertical Measurements on Digital Orthopantomographs: Posterior Mandibular Region. J Clin Imaging Sci. 2014;4(2):7.

6. Devlin $\mathrm{H}$, Yuan J. Object position and image magnification in dental panoramic radiography: A theoretical analysis. Dentomaxillofacial Radiol. 2013 Jan;42(1):29951683.

7. Bornstein MM, Horner K, Jacobs R. Use of cone beam computed tomography in implant dentistry: current concepts, indications and limitations for clinical practice and research. Vol. 73, Periodontology 2000. Blackwell Munksgaard; 2017. p. 51-72.

8. Harris D, Horner K, Gröndahl K, Jacobs R, Helmrot E, Benic Gl, et al. E.A.O. guidelines for the use of diagnostic imaging in implant dentistry 2011. A consensus workshop organized by the European Association for Osseointegration at the Medical University of Warsaw. Clin Oral Implants Res. 2012 Nov;23(11):1243-53.

9. European Commission. Protection radiation No 172: Cone beam CT for dental and maxillofacial radiology (Evidence-based guidelines) [Internet]. Luxembourg; 2012. Available from: http://www. sedentexct.eu/files/radiation_protection_172.pdf

10. European Commission. Radiation Protection No 136: European guidelines on radiation protection in dental radiology - The safe use of radiographs in dental practice [Internet]. Luxembourg; 2004. Available from: https://ec.europa.eu/energy/sites/ener/files/ documents/136.pdf

11. Benavides E, Rios HF, Ganz SD, An CH, Resnik R, Reardon GT, et al. Use of cone beam computed tomography in implant dentistry: The international congress of oral implantologists consensus report. Implant Dent. 2012;21(2):78-86.

12. Bornstein M, Scarfe W, Vaughn V, Jacobs R. Cone beam computed tomography in implant dentistry: A systematic review focusing on guidelines, indications, and radiation dose risks. Int J Oral Maxillofac Implants. 2014 Jan; 29(Supplement):55-77.

13. Horner K, O'Malley L, Taylor K, Glenny A-M. Guidelines for clinical use of CBCT: a review. Dentomaxillofac Radiol. 2015;44(1):20140225.
14. Noffke C, Farman A, Nel S, Nzima N. Guidelines for the safe use of dental and maxillofacial CBCT: a review with recommendations for South Africa. SADJ. 2011;66(6):264-6.

15. Singh R, Singh S, Nabi AT, Huda I, Singh D. Evaluation of existing radiographic prescription tendencies in planning dental implant therapy: A survey based original study. J Adv Med Dent Sci Res. 2019;7(1):100-3.

16. Shewale A, Gattani D, Gudadhe B, Meshram S. Radiographic imaging assessment prior to implant placement - Choice of dentists in Nagpur city. Indian J Dent Adv. 2017;9(3):139-43.

17. Ramakrishnan P, Shafi FM, Subhash A, Kumara AEG, Chakkarayan $\mathrm{J}$, Vengalath $\mathrm{J}$. A survey on radiographic prescription practices in dental implant assessment among dentists in Kerala, India. Oral Health Dent Manag. 2014 Sep;13(3):826-30.

18. Mall N, Pritam A. Assessment of current radiographic prescription trends in dental implant treatment planning: A survey based original study. Int J Med Heal Res. 2017;3(9):66-9.

19. Sakakura C, Morais J, Loffredo L, Scaf G. A survey of radiographic prescription in dental implant assessment. Dentomaxillofacial Radiol. 2003 Nov;32(6):397-400.

20. Rabi H, Qirresh E, Rabi T. Radiographic prescription trends among Palestinian dentists for dental implant placement - A cross sectional survey. J Dent Probl Solut. 2017;11-4.

21. Majid I, Mukith ur Rahaman S, Sowbhagya M, Alikutty F, Kumar H. Radiographic prescription trends in dental implant site. J Dent Implant. 2014;4(2):140.

22. Alnahwi M, Alqarni A, Alqahtani R, Baher Baker M, Alshahrani FN. A survey on radiographic prescription practices in dental implant assessment. J Appl Dent Med Sci. 2017;3(1):148-56.

23. Dölekoğlu S, Fişekçioğlu E, illgüy M, Illgüy D. The usage of digital radiography and cone beam computed tomography among Turkish dentists. Dentomaxillofacial Radiol. 2011;40(6):379.

24. Di Murro B, Papi P, Passarelli PC, D'Addona A, Pompa G. Attitude in radiographic post-operative assessment of dental implants among Italian dentists: A cross-sectional survey. Antibiotics. 2020 May 7;9(5):234

25. Beshtawi K. Recommendations for the development of a framework for radiological imaging studies during implant therapy in SA [Internet]. University of the Western Cape; 2021. Available from: http://hdl.handle.net/11394/7744

\section{YOU ARE ONE PHONE CALL AWAY FROM A SOLUTION!}

\section{SPECHAL OFFER. (OCT 21 TOMARROH 22)}

\section{LEI US DEAL WITH YOURE)}

\section{*Importing and Exporting Anguish!}

- Procurement of goods for business use

- Freight Forwarding (By air and road)/Logistics

- Customs Clearing

Look no more - we offer best services for all your medical and dental consumables and equipment

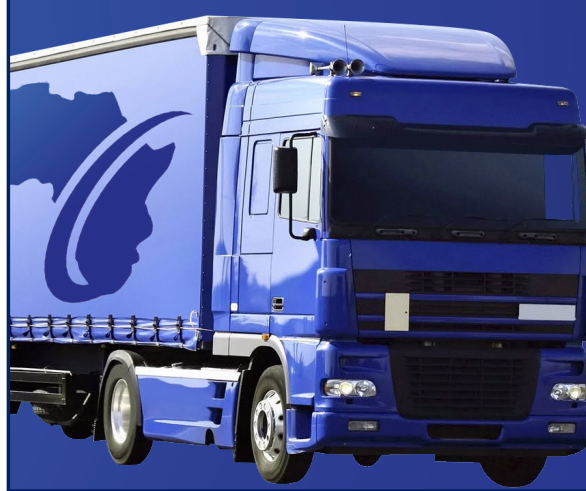

*We service South Africa, neighbouring SADC countries and other parts of Africa.

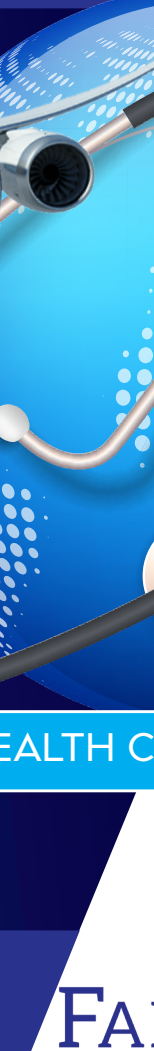
FAITUM PROJECTS \& SERVICES 